Borneo Journal of Science \& Technology, Volume (2), Issue (2), Pages: 27-33

DOI: http://doi.org/10.3570/bjost.2020.2.2-05

e-ISSN: 2672-7439

(C) 2018, UCTS Publisher.

Submitted: $31^{\text {th }}$ January 2020

Accepted: 02 ${ }^{\text {nd }}$ April 2020

Published: $31^{\text {th }}$ July 2020

\title{
Electricity Transmission across South China Sea by Suspending Cables within Oil and Gas Pipes
}

\author{
${ }^{*}$ Sung Chee Cheng, ${ }^{2}$ Prashobh Karunakaran, ${ }^{1}$ Vayalooran Karuppanna, ${ }^{1}$ Auriel Richard \\ ${ }^{1}$ Kolej Laila Taib (KLT), 96000 Sibu, Sarawak, Malaysia \\ ${ }^{2}$ School of Engineering Technology, University of Technology Sarawak (UCTS), \\ 96000 Sibu, Sarawak, Malaysia
}

\begin{abstract}
This paper presents research that will enable a $630 \mathrm{~km}$ submarine transmission of electricity at $1000 \mathrm{kV}$ 546 A high voltage alternating/direct current (HVAC) using an electric cable suspended within a carbon steel pipe. The research looks at the eddy current loss on the pipe by injecting AC current into the cable and measuring the temperature of the pipe using a thermal imaging camera. A distributed element model of the long transmission line is also used to calculate its transmission efficiency. An investigation with oil and gas contractors reveal that Highdensity polyethylene can replace carbon steel, resulting in cheaper material costs and eliminating the possibility of arcing between the cable and pipe. It is concluded high voltage AC is not the best method for transmission for this case. Similar research will need to be done for DC current.
\end{abstract}

Keywords: Submarine Transmission, Undersea, HVAC, Eddy Current Loss.

\section{INTRODUCTION}

The equatorial region has the highest amount of rainfall in the world. Sarawak, with its location at the equator and with its hilly interiors that can act as a natural barrier for dam construction, has an immense potential for hydroelectricity. Currently Sarawak has three hydroelectric dams and is planning to build another ten, which will put Sarawak at a 7,000 MW generating capacity [1].

In order to successfully enable the utilisation of other forms of renewable energy, a large electric grid is imperative in order to connect up renewable energies from other regions.

The following two neighboring countries, with potential in their own respective renewable energies, are candidates of this grid, along with Sarawak.

(i) The Philippines is the largest wind power generator in ASEAN with an operation capacity of $400 \mathrm{MW}$ and is planning to increase the capacity to 1,600 MW (Saurabh, 2016) and has significant potential to provide up to $76,000 \mathrm{MW}$. Its geothermal capacity is at $1,868 \mathrm{MW}$.

(ii) Indonesia has reached an installed geothermal power generation capacity of 1,925 MW and has reserves of 17,506 MW and potential resources of $11,073 \mathrm{MW}$ and is projected to become the world's largest geothermal power producer by 2023 .
Similar solution, called the Synchronous Grid of Continental Europe (SGCE), was formulated in Europe which connects the grids of 24 countries [2]. The ASEAN grid could be used to provide renewable energy to load centers for her members, and to further interconnect and integrate the renewable energies to the existing grid electricity produced by traditional means. The concept is feasible as shown in Figure 1 as the Sunda Shelf is relatively shallow for undersea interconnections purpose.

The main problem for such an ASEAN spanning grid is the exorbitant cost of the submarine XLPE based cable [1]. Other factor that is considered is whether to transmit the electricity in AC or DC. AC transmission is most ideal as the infrastructures are already in place. However, limitation such as cable losses under AC condition, may render the transmission totally unfeasible. DC transmission solves many of the problems encountered with $\mathrm{AC}$ at the expense of building costly converter stations.

Corresponding Author: Sung Chee Cheng, Kolej Laila Taib (KLT), E-mail: ccs21@ hotmail.com 


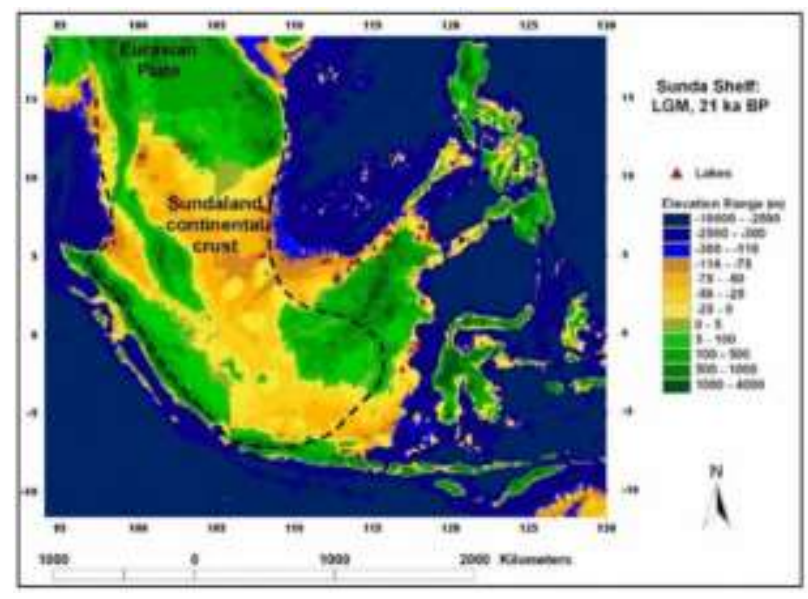

Figure 1: The depth of the Sunda Shelf on which sit the ASEAN member countries [Bulletin of the

Geographical Society of Malaysia, Volume 62, December 2016]

The longest submarine cable in the world is 580 $\mathrm{km}$ long carrying HVDC $700 \mathrm{MW}$ at $525 \mathrm{kV}$ between Norway and the Netherlands whereas the longest $\mathrm{O} / \mathrm{H}$ transmission lines is $730 \mathrm{~km}$ long carrying HVAC 9000 MW at $1000 \mathrm{kV}$ between Xilingol League and Shandong in China. As can be noted the $\mathrm{O} / \mathrm{H}$ transmission lines can carry 12.8 times more power over 1.2 times the distance of submarine cables.

$\mathrm{U} / \mathrm{G}$ (underground) cables also fail at much higher rates than $\mathrm{O} / \mathrm{H}$ (overhead) lines [3]. $\mathrm{O} / \mathrm{H}$ lines can have a continuous service lifespan of over 80 years compared to five years for $U / G$ cables [4]. Empirically, the weakest points in U/G cables are the joints [1] and one can expect the same problem with submarine cables. $\mathrm{U} / \mathrm{G}$ cables also cost 400 times more than $\mathrm{O} / \mathrm{H}$ lines [4].

This research aims to create and investigate an $\mathrm{O} / \mathrm{H}$ line environment by suspending an electric cable within carbon steel pipes with air insulation instead of the dielectric insulation (i.e. XLPE) of traditional cable. The result will help in the implementation of the 630 $\mathrm{km}$ transmission distance between Kuching and Johor Bahru which is a first step towards the ASEAN grid.

The postulated design is shown in Figure 2. A conductor cable is held at the center of the carbon steel pipe by three ceramic insulators per unit length.

The cavity is filled with a mixture of $\mathrm{N}_{2} / \mathrm{SF}_{6}$ at $20 \% \mathrm{SF}_{6}$ resulting in an insulating capability of 70 to $80 \%$ of pure $\mathrm{SF}_{6}$ at the same gas pressure [5]. The purpose of the gas mixture is 3 fold.

(i) To act as an insulator between the conductor cable and carbon steel pipe.

(ii) Displaces $\mathrm{O}_{2}$ thereby preventing corrosion.

(iii) Forced circulation dissipates heat from the cable but considering the temperature at the seabed is $22^{\circ} \mathrm{C}$ heat dissipation is expected to not become a problem.

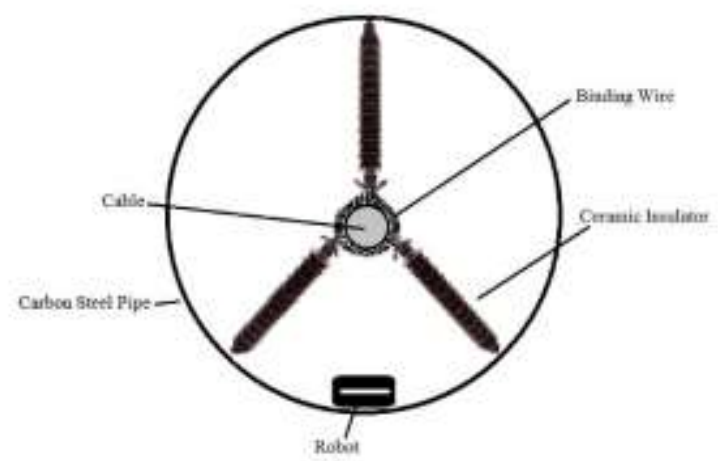

Figure 2: Cross sectional area of the pipe

According to existing literatures this design is very similar to the GIL (Gas Insulated Line, see Figure 3) developed by Siemens but using two insulators per unit length. There is a lack of information on the application of this technology for distance over $20 \mathrm{~km}$ long, even more so at length of several hundred kilometers the information is non-existent. The GIL is not suitable for our purpose due to the cost since it is from Germany and two insulators per unit length holding the cable may not be stable in a $630 \mathrm{~km}$ long transmission hence the proposed alternative shown in Figure 2.

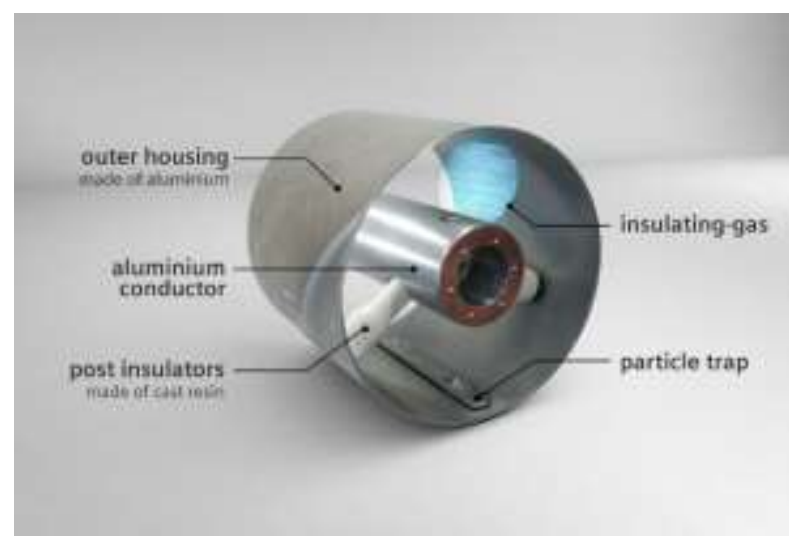

Figure 3: A cross section view of a modern GIL showing its various components (Source: Siemens website)

This research envisions the $630 \mathrm{~km}$ transmission voltage to be at $1000 \mathrm{kV} \mathrm{AC}$ and the $500 \mathrm{~mm}^{2}(\varnothing=$ $1.262 \mathrm{~cm}$ ) conductor cable to handle 546 A giving a power transfer capability of $546 \mathrm{MW}$. 


\section{THEORY}

An analysis on the electrical nature of the cable-pipe forming a coaxial configuration as shown in Figure 1 is carried out.

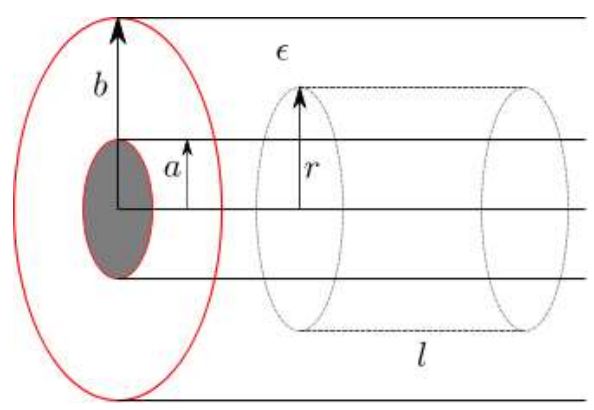

Figure 1: The dimension of the cable-pipe coaxial configuration

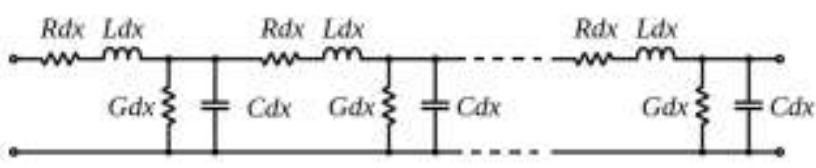

Figure 2: The distributed element model of a long transmission line where the $d x$ indicates an incremental length

By treating the configuration as a long transmission line and using electromagnetic theory on the coaxial dimensions, the following parameters can be determined for the distributed element model of Figure 2 that is used for the analysis.

$a=$ radius of conductor cable

$b=$ inner radius of carbon steel pipe

$\mathrm{R}=$ line resistance per unit length

$\mathrm{L}=$ line inductance per unit length $=\frac{\mu}{2 \pi} \ln \frac{b}{a}$

$z=$ line impedance per unit length $=R+j \omega L$

$\mathrm{G}=$ shunt conductance (or leakage) per unit length $=\frac{C}{\rho \varepsilon}, \rho=$ resistivity of insulating media in cavity

$\mathrm{C}=$ line capacitance per unit length $=\frac{2 \pi \varepsilon}{\ln \frac{b}{a}}$

$y=$ line shunt admittance per unit length $=G+j \omega C$

$\ell=$ length of line $=630000 \mathrm{~m}$

$\mathrm{Z}=$ total series impedance of line $=z \times \ell$

$\mathrm{Y}=$ total shunt admittance of line $=y \times \ell$

$$
\begin{aligned}
& \gamma=\sqrt{z \times y}=\sqrt{(R+j \omega L)(G+j \omega C)} \\
& Z_{0}=\sqrt{\frac{z}{y}}=\sqrt{\frac{R+j \omega L}{G+j \omega C}}
\end{aligned}
$$

The voltage and current from the sending-end of the transmission line are respectively given by:

$$
\begin{aligned}
& V_{S}=V_{R} \cosh \gamma \ell+I_{R} Z_{0} \sinh \gamma \ell \\
& I_{S}=I_{R} \cosh \gamma \ell+\frac{V_{R}}{Z_{0}} \sinh \gamma \ell
\end{aligned}
$$

where $V_{R}$ and $I_{R}$ are the receiving-end quantities. The efficiency of electricity transmission can be calculated with:

$$
\text { Efficiency of transmission }=\frac{\text { power received }}{\text { power sent }}
$$

However, the distributed element model theory of Figure 2 does not account for the eddy current loss on the carbon steel pipe. This is because the loss is unrelated to the effects of the distributed elements of the model but to the flux linkage between the magnetic field of conductor current and the carbon steel pipe. The set of equations (1) does not include this information.

The alternating magnetic field in the carbon steel pipes induces an electromotive force (emf) within the pipes according to Faraday's Law of electromagnetic induction. The emf causes circulating current to form within the pipes which technically is called eddy current. The eddy current causes the pipe to heat up which the researchers can measure the temperatures of with a FLIR (thermal imaging) camera. This unwanted heat is called eddy current loss.

The eddy current loss can be reduced to a negligible level if the diameter of the carbon steel pipe is large enough to minimise the magnetic field in the carbon steel as the magnetic field density for a long straight conductor is inversely proportional to its distance from the conductor.

\section{METHODOLOGY}

Since the AC current in the cable produces an alternating magnetic field in the carbon steel pipe which in turn induces eddy currents in the pipe, the investigation will be on the eddy current loss in the pipes. This is significant as eddy current loss causes energy wastage resulting in a lowered transmission efficiency.

Since direct measurement of this eddy current loss is not possible, an indirect measurement using a FLIR Camera to measure the temperature of the pipe as 
shown in Figure 3 is employed. Higher temperature corresponds to higher eddy current loss which correlates to higher energy wastage.

Four $2.5 \mathrm{~mm}^{2}, 3 \mathrm{~m}$ long $\mathrm{Cu}$ wires were stripped of insulator and intertwined to form the cable conductor. Eight carbon steel pipes of different diameters were purchased, with $92 \mathrm{~cm}$ in length each, as shown in Figure 4. The pipe diameters are specified in Table 1. A wooden support was built. The cable is suspended in the middle of a pipe with the help of the support as shown in Figure 4.

The use of $\mathrm{N}_{2} / \mathrm{SF}_{6}$ gas mixture is omitted from the experiment because it does not affect the alternating magnetic field density in the carbon steel pipes which gives rise to the eddy current loss. Atmospheric air is used as insulation as the pipes are open ended.

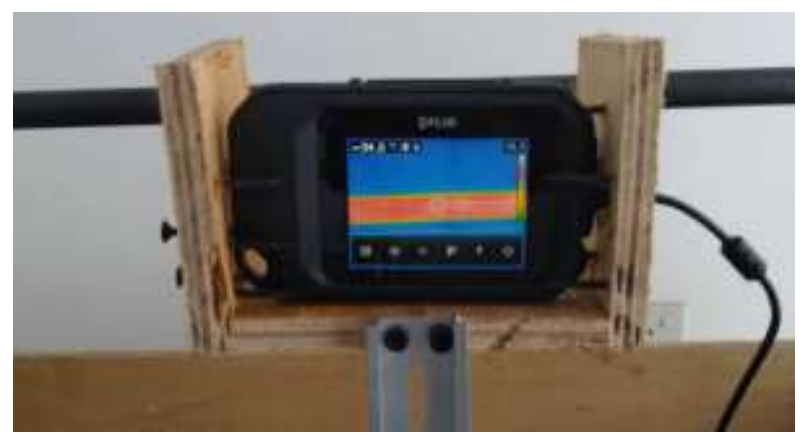

Figure 3: FLIR camera showing the temperature gradient on a pipe

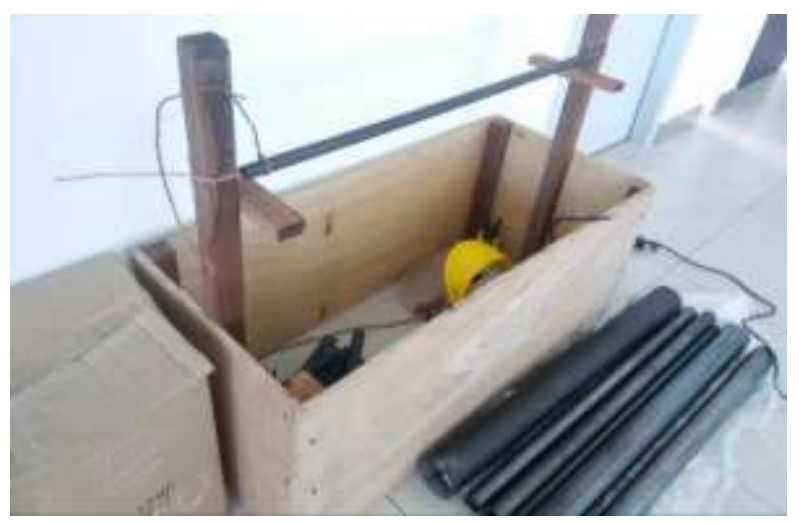

Figure 4: Wooden support showing six carbon steel pipes

One end of the cable is connected to a $\mathrm{MCCB} / \mathrm{Isolator}$ combination using copper wirings. The other end is connected to a load of 132 incandescent bulbs of $100 \mathrm{~W}$ each giving a maximum $13.2 \mathrm{~kW}$ load. The bulbs are connected in 11 parallel rungs with 12 bulbs to each rung as shown in Figure 7. A switch is connected to the incoming of each rung. Each rung takes $5 \mathrm{~A}$ current. The overall schematic is shown in Figure 8.

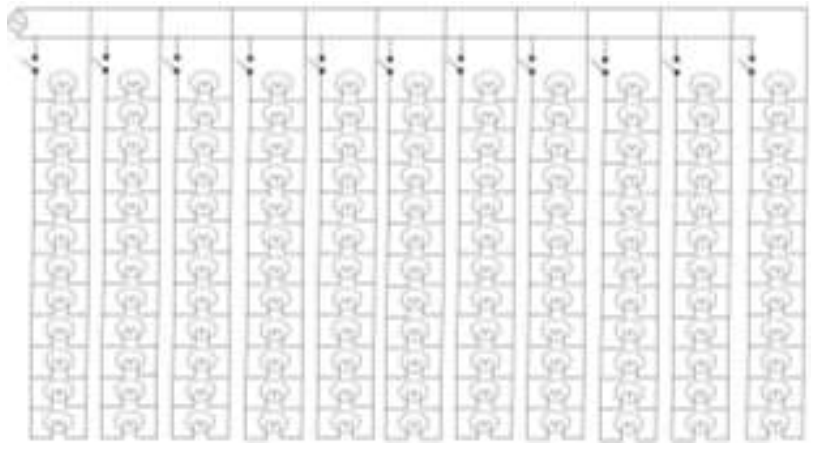

Figure 7: How the 132 bulbs are connected as a load. Each rung controls 5 A current

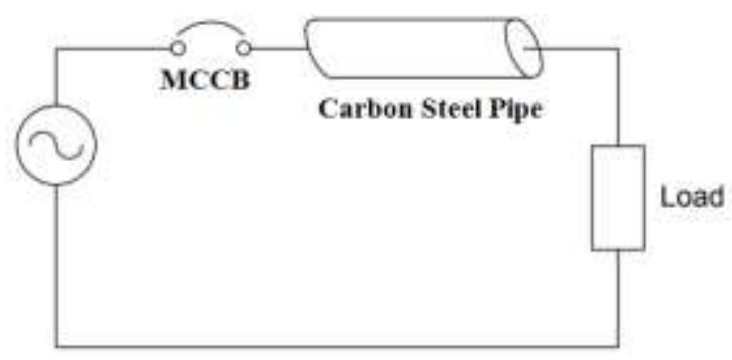

Figure 8: Schematic diagram of the experiment setup for temperature measurement on the carbon steel pipes

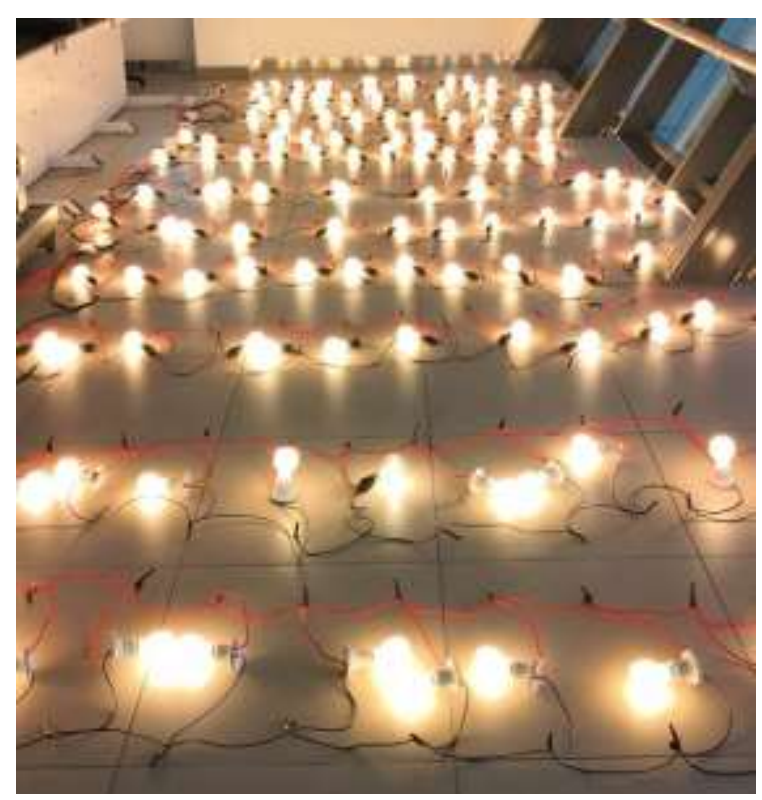

Figure 9: All rungs powered on

The first temperature measurements are made on the smallest pipe with the full load of 11 rungs powered on (see Figure 9). A temperature reading is taken with the FLIR camera (see Figure 3) after 30 minutes. Next, a rung is switched off. After 30 minutes the second 
reading is taken and so forth until a reading has been taken for every rung switched off. Then the pipe is exchanged with the next larger diameter and the process is repeated until readings have been taken for all pipes. The results are tabulated in Table 1.

\section{RESULTS AND DISCUSSION}

Table 1 shows the result of the temperature readings on the carbon steel pipes. The 5 A column indicates one rung is switched on. Switching on a rung adds $5 \mathrm{~A}$ of current flowing in the circuit, and the highest current is 55 A with all the 11 rungs switched on. It is noted that for pipe \#8 for $55 \mathrm{~A}$ the temperature rise reduces drastically.

Taking the average temperature rise per pipe under the $55 \mathrm{~A}$ column and correlating it with the average diameter increase per pipe, a vertical linear extrapolation as seen in Table 2 shows at $\varnothing=20.32 \mathrm{~cm}$ $=8$ " there would be minimal temperature rise for $55 \mathrm{~A}$ current. This value is the minimum carbon steel pipe diameter to minimise the eddy current loss at $55 \mathrm{~A}$.

The researchers are looking into another data collection period with better control, such as barriers to stop drafts, in place. With better data the researchers will perform a horizontal extrapolation to reach temperature for $546 \mathrm{~A}$, and subsequently a vertical extrapolation to reach pipe diameter that will minimise eddy current loss for this current.

Microsoft Excel calculation using the distributed element model theory with air insulation predicts the efficiency of the $630 \mathrm{~km} \mathrm{HVAC}$ transmission using carbon steel pipe to be less than $50 \%$.

Even with the carbon steel replaced with HDPE the transmission efficiency is similar.
However, when the frequency variable is set to zero for a HVDC the transmission efficiency is $98 \%$.

The low AC transmission efficiency is due to the shunt loss in the model which is significant due to the length of the transmission. The solution in eliminating shunt loss is to use DC with the frequency variable set to zero.

Because the magnetic field from a DC current is static, there is also no eddy current loss in the carbon steel pipe. With the design of Figure 2 and the O\&G pipe laying experience of local contractors it is possible to use HVDC to transmit electricity from Kuching to Johor Bahru, be it with carbon steel or HDPE pipes.

It is also suggested that the breakeven cost for AC-DC-AC converters is $50 \mathrm{~km}$ for submarine cables and $600 \mathrm{~km}$ for $\mathrm{O} / \mathrm{H}$ lines [6].

Furthermore, the power grid frequency of the Peninsular is slightly different from Sarawak's. Connecting grids of different frequencies will result in tripping and shut-down in the weaker grid system. Frequency synchronization needs to be done if the two power grids are to be interconnected thru HVAC. This would also require na AC-DC-AC converter.

Thus, the breakeven cost and the problem of synchronisation both support HVDC transmission over HVAC.

Furthermore, without the skin effect in DC, the full cable can be utilised for current transfer which is $100 \%$ more from AC. So the power transfer capacity is $546 \mathrm{MW}$ X $2=1092 \mathrm{MW}$ and the current is $546 \mathrm{X} 2=$ 1092 A [6].

Table 1: Result of temperature reading vs pipe diameter and AC current in the conductor cable

\begin{tabular}{cccccccccccccc}
\hline \multirow{2}{*}{$\begin{array}{c}\text { Pipe } \\
\#\end{array}$} & $\begin{array}{c}\text { Pipe } \\
\text { Diameter } \\
(\mathrm{cm})\end{array}$ & \multicolumn{10}{c}{ Current $(\mathrm{A})$} \\
\cline { 3 - 13 } & & & 10 & 15 & 20 & \multicolumn{10}{c}{ Temperature $\left({ }^{\circ} \mathrm{C}\right)$} \\
\hline 1 & 2.18 & 31.0 & 31.1 & 31.5 & 33.4 & 34.7 & 36.6 & 37.6 & 40.8 & 42.7 & 44.3 & 47.4 \\
\hline 2 & 2.66 & 29.3 & 30.2 & 29.1 & 29.7 & 34.7 & 35.2 & 37.3 & 39.5 & 39.3 & 41.4 & 40.0 \\
\hline 3 & 3.37 & 29.1 & 29.1 & 29.7 & 20.1 & 31.3 & 31.8 & 32.3 & 33.8 & 34.6 & 35.7 & 35.7 \\
\hline 4 & 4.23 & 29.3 & 30.5 & 31.2 & 31.6 & 32.7 & 33.1 & 33.6 & 34.4 & 35.5 & 35.9 & 37.8 \\
\hline 5 & 4.84 & 30.6 & 31.4 & 32.3 & 32.4 & 32.6 & 33.7 & 34.0 & 34.8 & 35.3 & 35.5 & 35.7 \\
\hline 6 & 6.06 & 28.2 & 29.1 & 29.6 & 30.3 & 31.1 & 31.5 & 31.7 & 32.9 & 33.7 & 34.4 & 35.5 \\
\hline 7 & 7.56 & 29.0 & 28.6 & 29.4 & 29.9 & 30.0 & 30.2 & 30.2 & 30.5 & 30.6 & 31.0 & 32.3 \\
\hline 8 & 8.81 & 26.9 & 27.5 & 27.3 & 27.3 & 27.7 & 28.3 & 29.6 & 29.6 & 30.2 & 30.5 & 30.8 \\
\hline
\end{tabular}


Electricity Transmission Across South China Sea By Suspending Cables Within Oil and Gas Pipes

Table 2: Vertical extrapolation of data to reach diameter for $55 \mathrm{~A}$

\begin{tabular}{|c|c|c|c|c|c|c|}
\hline & $\begin{array}{c}\text { Biggest } \varnothing \\
\text { - smallest } \\
\varnothing=\end{array}$ & 6.63 & & $\begin{array}{l}\text { Highest }{ }^{\circ} \mathrm{C}- \\
\text { lowest }{ }^{\circ} \mathrm{C}=\end{array}$ & 16.6 & \\
\hline & $\begin{array}{c}\text { Average } \\
\text { difference } \\
\text { in } \varnothing= \\
\varnothing / 7=\end{array}$ & 0.947 & & $\begin{array}{l}\text { Difference } \\
\text { in }{ }^{\circ} \mathrm{C} / 7=\end{array}$ & 2.371 & \\
\hline $\begin{array}{l}\text { Pipe } \\
\#\end{array}$ & $\begin{array}{c}\text { Pipe } \varnothing \\
\text { Original } \\
\text { data }\end{array}$ & $\begin{array}{l}\text { Add } \\
0.947 \text { to } \\
\text { this } \\
\text { row's } \\
\text { pipe } \varnothing \\
\text { (right } \\
\text { column) } \\
\text { to get } \\
\text { next } \\
\text { row } \\
\text { pipe } \varnothing\end{array}$ & $\begin{array}{c}\text { How many } \\
\text { rows to add to } \\
\text { reach } \\
\varnothing=8 "=20.32 \mathrm{~cm}\end{array}$ & $\begin{array}{l}\text { Temperature } \\
\text { on pipe } \\
\text { Original } \\
\text { data }\end{array}$ & $\begin{array}{l}\text { Deduct } \\
\text { this } \\
\text { number } \\
\text { to get } \\
\text { next }{ }^{\circ} \mathrm{C} \\
\text { (right } \\
\text { column) }\end{array}$ & $\begin{array}{l}{ }^{\circ} \mathrm{C} \text { on pipe } \\
\text { by Excel } \\
\text { extrapolation }\end{array}$ \\
\hline 1 & 2.180 & & 2.180 & 47.400 & & 47.400 \\
\hline 2 & 2.660 & 0.947 & 3.127 & 40.000 & 2.371 & 45.029 \\
\hline 3 & 3.370 & 0.947 & 4.074 & 35.700 & 2.371 & 42.657 \\
\hline 4 & 4.230 & 0.947 & 5.021 & 37.800 & 2.371 & 40.286 \\
\hline 5 & 4.840 & 0.947 & 5.969 & 35.700 & 2.371 & 37.914 \\
\hline 6 & 6.060 & 0.947 & 6.916 & 35.500 & 2.371 & 35.543 \\
\hline 7 & 7.560 & 0.947 & 7.863 & 32.300 & 2.371 & 33.171 \\
\hline 8 & 8.810 & 0.947 & 8.810 & 30.800 & 2.371 & 30.800 \\
\hline & & 0.947 & 9.757 & & 2.371 & 28.429 \\
\hline & & 0.947 & 10.704 & & 2.371 & 26.057 \\
\hline & & 0.947 & 11.651 & & 2.371 & 23.686 \\
\hline & & 0.947 & 12.599 & & 2.371 & 21.314 \\
\hline & & 0.947 & 13.546 & & 2.371 & 18.943 \\
\hline & & 0.947 & 14.493 & & 2.371 & 16.571 \\
\hline & & 0.947 & 15.440 & & 2.371 & 14.200 \\
\hline & & 0.947 & 16.386 & & 2.371 & 11.829 \\
\hline & & 0.947 & 17.334 & & 2.371 & 9.457 \\
\hline & & 0.947 & 18.281 & & 2.371 & 7.086 \\
\hline & & 0.947 & 19.229 & & 2.371 & 4.714 \\
\hline & & 0.947 & 20.176 & & 2.371 & 2.343 \\
\hline & & 0.947 & 21.123 & & 2.371 & -0.029 \\
\hline
\end{tabular}

\section{CONCLUSION}

As the spacing between the cable and the pipe wall is increased the eddy current losses are reduced as indicated by the lowered temperature readings from the FLIR camera. The experiment predicts a pipe diameter $\varnothing=20.32 \mathrm{~cm}$ for $\mathrm{AC}$ current $55 \mathrm{~A}$ will give no appreciable eddy current loss in the carbon steel pipe.

However, using the result $\varnothing=20.32 \mathrm{~cm}$ the distributed element model predicts the transmission of HVAC using a cable suspended in O\&G pipes across630 $\mathrm{km}$ is not efficient even though the eddy current loss has been reduced to a minimum for this diameter.

The other option is to use HVDC for the transmission which solves the eddy current and the shunt loss problem.

Similar research involving measuring the temperatures on the carbon steel pipes when the injected current is DC would need to be carried out to confirm HVDC as the viable option of electricity transmission.

It should be noted that FRP (Fiber Reinforced Plastic) is to replace the initially suggested ceramics 
(see Figure 2) as support insulators. FRPs are superior in terms of their strength to weight ratio and are not easily fractured during installation due to bending stresses.

The $\mathrm{N}_{2} / \mathrm{SF}_{6}$ insulating gas will be replaced with pure $\mathrm{N}_{2}$ gas due to cost reason and the concern that $\mathrm{SF}_{6}$ is a very potent greenhouse gas the handling of which requires strict adherence to regulations [7].

According to experienced $\mathrm{O} \& \mathrm{G}$ pipe laying contractors Song Tung Hieng, Professional Engineer Aprianto Bin Soegiarto and Nyandang Bulik on the procedures of laying down O\&G pipes on the seabed, it is possible to lay down a pipe from Kuching to Johor. The estimated cost, including labour charges of various professionals, is $\$ 1.2$ billion. The estimated time duration, including downtime and bad weather, is nine months [8].

Carbon steel pipes are available in $\varnothing=4$ " (= $10.16 \mathrm{~cm}), 6 "(=15.24 \mathrm{~cm}), 8 "(=20.32 \mathrm{~cm})$ all the way to $36 "(=91.44 \mathrm{~cm})$. 12" $(=30.48 \mathrm{~cm})$ and $24 "$ (= $60.96 \mathrm{~cm})$ are particularly specified for gas. There are also 64" (= $162.56 \mathrm{~cm})$ and 72" (= $182.88 \mathrm{~cm})$. Most of the main lines are 24", with 4" to 6" mostly for processing gas on the oil platform [8].

From a follow up interview via a conference call to a professional engineer from a subsea piping consulting company, Bennet, it was made known that the latest technology for O\&G is HDPE (High-density Polyethylene) pipes, which are yet to be used in Sarawak. This material is ideal for this project as it is an insulator and completely eliminates the eddy current loss as well as the drastic reduction in weights, material cost, and installation cost. The lifespan of HDPE pipes is 20 years but without the abrasion and pressure (100200 bar) within normally encountered in petroleum carrying pipes a 100 years lifespan is possible [8]; [9].

\section{ACKNOWLEDGMENT}

This research is fully supported by UCTS (University College of Technology Sarawak) University Research Grant, Ref. UCTS/RESEARCH/4/2017/14. The author thanks his supervisor for his ideas and contributions.

\section{REFERENCES}

[1] Karunakaran, Prashobh (2015). The Options And Design Improvements Of The Electric Grid Of Sarawak As An Example For Developing Countries, Global Journal of Engineering Science and Researches, Volume 2, Issue 6. P161-170. ISSN 2348 - 8034

[2] Karunakaran, P., Osman, M. S., Lau, A. K., Lee, M. D., \& Kumar, P. (2017, September). Underwater Electricity Transmission using Electric Cables Suspended within Carbon Steel Pipes. In 2017 International Conference on Current Trends in Computer, Electrical, Electronics and Communication (CTCEEC) (pp. 1247-1253). IEEE.

[3] Barron, O., Silberstein, R., Ali, R., Donohue, R., McFarlane, D. J., Davies, P. \& Donn, M. (2012). Climate change effects on water-dependent ecosystems in south-western Australia. Journal of Hydrology, 434, 95-109.

[4] Thue, W. A. (2016). Electrical power cable engineering. CRC Press.

[5] L.G. Christophorou, R.J. Brunt, SF6:N2 Mixtures, Basic and HV Insulation Properties, IEEE Transactions, Dielectrics and Electrical Insulation 2 (5) (October 1995) 952-1002.

[6] Narayan, R. S., Mohan, S., \& Sunitha, K. (2017). Simulative Study into the Development of a Hybrid HVDC System Through a Comparative Research with HVAC: a Futuristic Approach. Engineering, Technology \& Applied Science Research, 7(3), 1600-1604.

[7] Standard, I.E.C., 2008. 62271-303:'High-voltage switchgear and controlgear - Part 303: Use and handling of sulphur hexafluoride (SF 6)'.

[8] Song Tung Hieng, Aprianto Bin Soegiarto PE, Nyandang Bulik. (2018, December 30). Personal interview except for Aprianto with conference call.

[9] Iannuzzi, M., Barnoush, A., \& Johnsen, R. (2017). Materials and corrosion trends in offshore and subsea oil and gas production. Materials Degradation, 1(1), 2. 